\title{
Analysis of building information modeling technologies for transport infrastructure objects at the stages of the life cycle
}

\author{
Maksim Zheleznov, Liubov Adamtsevich*, Pavel Vorobiev and Angelina Rybakova \\ Moscow State University of Civil Engineering, Yaroslavskoe shosse, 26, Moscow, 129337, Russia
}

\begin{abstract}
The expansion of the transport system is one of the urgent tasks of the development of the Russian economy. The high level of transport infrastructure quality ensures the development of many areas of business, simplifies the procedure for transporting goods, and also creates comfortable conditions for the movement of passengers. For the progression of the transport system, it is necessary to regularly increase the number of objects, which in turn forms an increase in the volume of transport construction. The current design and construction approaches do not provide a sufficient level of fast and high-quality construction of facilities, therefore, the introduction of modern work methods is an urgent issue. Information modeling technologies are currently one of the promising areas of digitalization, but in the field of transport construction they have not yet received sufficient application. The purpose of this research work is to analyze the use of information modeling technologies for transport infrastructure objects at all stages of the life cycle, and the task is to determine the processes for implementation through the information modeling functionality. The paper outlines the main features of transport infrastructure facilities, the specifics of work based on information modeling, and also analyzes their integration throughout the entire life cycle. As a result, an analysis of the effectiveness of the use of information modeling technology tools for the main tasks of each stage of the life cycle is presented, and an information transfer algorithm is formed.
\end{abstract}

\section{Introduction}

Information Modeling Technologies (BIM) is a complex of interrelated processes based on the use of intelligent 3D models that include the maximum amount of information about the future object. Information Modeling covers all stages of the life cycle: from concept to operation and, increasingly, even to dismantling. The purpose of information modeling technology is to impoverish all processes of urban planning activities. BIM technologies are

\footnotetext{
* Corresponding author: AdamtsevichLA@gmail.com
} 
one of the most promising areas not only in the construction industry, but in related engineering sciences.

Initially, the spread of information modeling technologies was limited only to capital construction facilities, but today it is widely used in the construction of transport infrastructure facilities. The implementation of BIM technology in transport has a number of differences and limitations, however, with the rational use of the tools of BIM software systems, the work is performed with maximum efficiency. Therefore, it is necessary to formulate the features of the construction of transport infrastructure facilities, as directions of the development day and new ways of implementing information modeling technologies.

Information modeling technologies in transport include not only BIM software tools, but also Big Data and cloud computing technologies, as well as modern analysis tools. Work within the BIM framework adjusts the processes of interaction of interested specialists, almost completely changes the approaches to the complex development of objects.

Transport infrastructure facilities can be globally divided into two types: linear facilities and capital facilities (transport hubs, railway stations, bridges, junctions). The design approach for each group is certainly different. Capital objects of transport infrastructure are much similar in design and implementation to the main objects of capital construction, but they have a number of distinctive features: the location and design of these objects directly depend on the designed linear structures.

The main feature of linear structures from other types of objects is their significant spatial extent. In this regard, before designing, it is necessary to solve a number of problems related to the location of the routes: variable design of linear objects, analysis of options in terms of technical, financial, environmental, climatic, social efficiency, and making a decision on the most rational option.

Successful multivariate analysis will ensure not only the choice of the most effective design solution, but also significantly simplify the work on the development of the project in the future, which will allow to perform a large amount of design in a short time. Achieving this goal is impossible without the use of automation tools for collecting and processing information, design and construction.

Thus, the introduction of information modeling technologies for transport infrastructure facilities at all stages of the life cycle can ensure a high level of quality of facilities, speed up a number of design processes and simplify maintenance in operation, which is an important and urgent task in the construction of transport facilities.

\section{Methods}

\subsection{Transport infrastructure facilities}

The transport infrastructure is a complex of all transport enterprises that carry out and service the transportation of the population and goods. The classification of transport infrastructure elements can be defined in several categories, according to purpose, belonging, tasks to be solved. (Table 1) Systematization of transport facilities is the foundation for the development of each direction, for the search for new ways of implementing facilities and new techniques. 
Table 1. Classification of transport infrastructure elements

\begin{tabular}{|c|c|c|}
\hline № & Classification category & Classes \\
\hline 1 & Mode of transport & Cars \\
& & Railway \\
& & Nautical \\
& & Aviation \\
& & Pipeline \\
\hline 2 & The main aim & Passenger \\
& & Cargo \\
& & Operational \\
& & Logistic \\
\hline 3 & Territorial affiliation & Federal \\
& & Urban \\
& & Special \\
& & Municipal \\
\hline 4 & Location level & Overground \\
& & Underground \\
\hline 5 & Dynamics & Static \\
& & Dynamic \\
\hline 6 & Users & Common use \\
& & State \\
& & Corporate \\
& & Private \\
\hline
\end{tabular}

Some objects can simultaneously belong to several categories, thereby performing additional functions. When considering the classification of objects from the point of view of implementation based on information modeling technologies, three categories can be divided:

1. Linear objects requiring extended study at a great distance. Software systems have the ability to simulate routes and highways in full length, taking into account the peculiarities of zoning, terrain and geodetic marks. This information is provided based on the results of engineering surveys presented in the geological information model. Sections, road surface compositions and drawings of assemblies and fasteners are obtained automatically and can, if necessary, be corrected in the shortest possible time.

2. Capital point facilities, the design methodology of which fully coincides with the design of capital construction facilities. The difference is only at the pre-design stage due to the dependence on linear objects. In most cases, these objects are generic and their designs can be reused. When implementing this type of objects, information modeling makes it possible to most effectively integrate linear objects into the environment with the ability to quickly adapt to their characteristics.

3. Objects that cannot or do not need to be implemented using information modeling tools.

The maximum use of information from the pre-design stage at the design stage significantly reduces the amount of work both directly developing an integrated information model and analyzing and choosing options for design solutions. In addition to the technical characteristics of the future object, the information model reflects its influence on socioeconomic, environmental, technologically and other factors. which have a close relationship with each other. 


\subsection{Life cycle of transport infrastructure objects}

The life cycle of any object is the period of time during which it exists as an object of interest: from idea to dismantling. Typically, the life cycle includes the following stages:

1. Investment

2. Pre-design development

3. Project

4. Construction

5. Operation

6. Dismantling

Each stage includes a corresponding set of tasks and requirements for them. However, depending on the object, there are qualitative and temporal differences.

The life cycle of a transport infrastructure object is a set of interrelated processes of creation, functioning and disposal of a transport object, which begin with the development of a concept and end with dismantling. Consequently, the life cycle of transport objects, similar to the life cycle of capital construction objects, includes the same stages, but within each stage there are significant differences in the goal, in the list of tasks, the implementation period and the final product (Fig. 1).

Based on the results of the analysis of the life cycle of transport facilities, it can be concluded that some stages can be repeated several times without damage to the facility itself, in contrast to capital construction facilities (modernization, modification, replacement of an element). An additional difference is also the requirements for the object.

One of the drawbacks of the existing life cycle system is the low level of information transfer about the transport object. The low volume of data at the last stages is due to the low level of elaboration of the information model at the initial stages. Insufficient use of the same data at interconnected stages is associated with the lack of functional algorithms for the effective transfer of information from stage to stage.

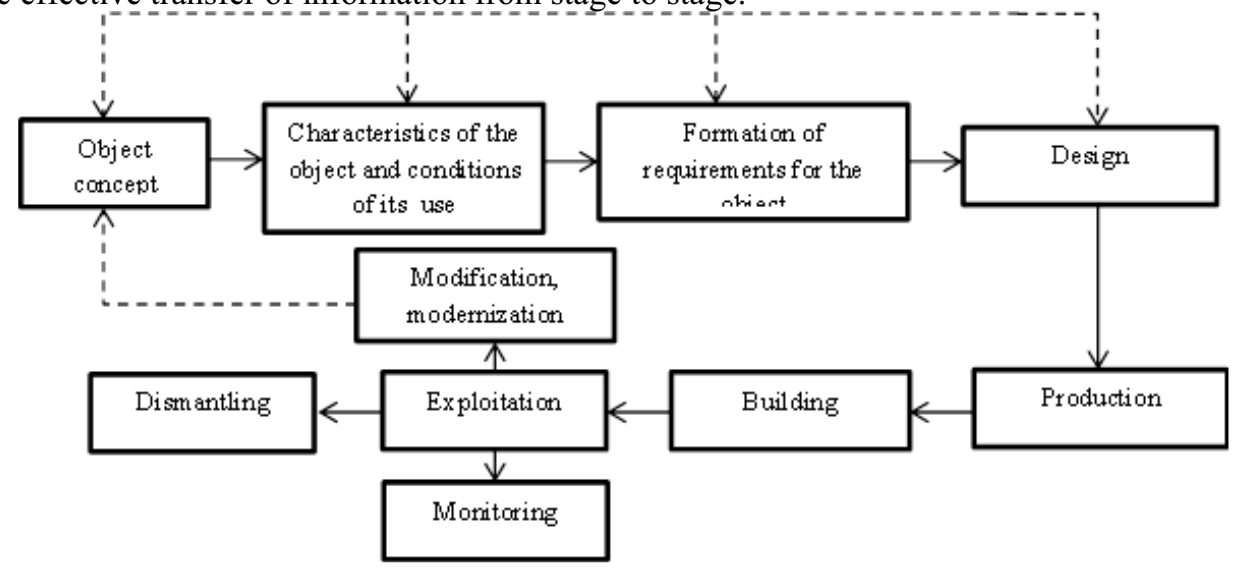

Fig. 1. Extended life cycle of transport infrastructure objects

\subsection{Information modeling technologies for transport infrastructure facilities}

Having information modeling software alone in the design process does not ensure production success. To obtain a positive effect of work, it is necessary to have adapted work algorithms, trained specialists, systematize the available information about the object. The concept of information modeling technologies implies not only design tools, but also 
an appropriate methodology for performing work, coordinating participants, organizing the construction and operation of an object. As part of the transport infrastructure work, the tools and methodology are limited by the specifics of the industry. Consequently, information modeling technologies in transport have their own specifics of design and construction.

Based on the existing information modeling capabilities, requirements for transport facilities and the characteristics of each stage of the life cycle, the following functions are determined:

- Integration of data from all stages of the trunk life cycle;

- Development of an information model of the road or its part, quick adjustment and updating;

- Simultaneous consistent management of all types of data;

- Using the information model as a single source of information for all stakeholders;

- Search and elimination of collisions;

- Simplified approval process;

- Integration of GIS data;

- Controlling the level of detail of the model;

- Visualization;

- Ubiquitous access;

- Construction control and architectural supervision based on digital data;

- Fast transfer of model data.

For each object, the level of execution of each function is significantly different. The reason for this may be the incompetence of some of the participants, the lack of a single work algorithm, a weak level of organization, etc. To improve the efficiency of information modeling of transport facilities, it is necessary not only to continuously improve the performance of each function, but also to perform new functions through BIM.

Existing information modeling software systems can be conditionally divided into four groups: architectural and structural (Autodesk Revit, ArchiCAD), GIS-design (CIVIL 3D, GeoniCS), for road design (Infraworks, IndorCAD, IndorRoad) and universal organizational (BIM360, Navisworks, ReCap). Each software package is used at the appropriate stage of the life cycle, taking into account the tasks to be solved and the functions performed. With the rational use of the information modeling tool, taking into account the specifics, technical and economic characteristics of the object and the existing financial and time constraints, the most effective work of the project team is built.

\section{Results}

The effectiveness of information modeling tools is determined by maximizing the use of accumulated data from previous stages. As a consequence, the quality of each stage is formed on the basis of the transfer of information. The volume of this information is summed up from the data obtained as a result of solving problems with tools of information modeling technologies. Some of the tasks within the stage are performed by a specific information modeling tool, which ultimately gives a total positive effect and a basis for further work. (Table 2). 
Table 2. Results of the application of information modeling technologies for transport infrastructure objects

\begin{tabular}{|c|c|c|c|}
\hline Stage & Tasks & Tool & Results \\
\hline $\begin{array}{l}\text { Pre-project } \\
\text { development / } \\
\text { concept }\end{array}$ & $\begin{array}{ll}\text { 1. } & \begin{array}{l}\text { Collection of initial } \\
\text { permits }\end{array} \\
\text { 2. } & \begin{array}{l}\text { Simplified approval } \\
\text { process; }\end{array} \\
\text { 3. } & \begin{array}{l}\text { Development of a } \\
\text { conceptual model }\end{array} \\
\text { 4. } & \text { Variable design } \\
\text { 5. } & \text { Integration of GIS data; } \\
\text { 6. } & \text { Simplified visualization; } \\
\text { 7. } & \text { Ubiquitous access. }\end{array}$ & $\begin{array}{c}\text { GeoniCS, } \\
\text { Infraworks, } \\
\text { ReCap, } \\
\text { Civil3D, } \\
\text { IndorCAD }\end{array}$ & 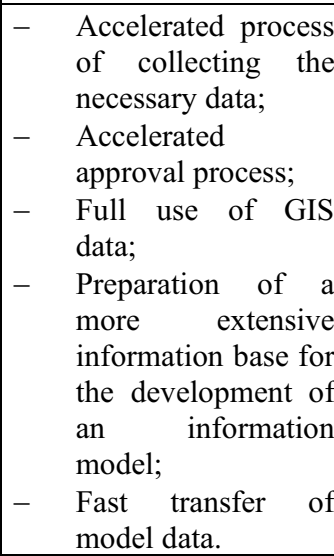 \\
\hline Design & $\begin{array}{l}\text { 1. Choosing a routing option } \\
\text { 2. Development of an } \\
\text { information model of the road } \\
\text { or its part } \\
\text { 3. Fast adjustment and updating; } \\
\text { 4. Simultaneous consistent } \\
\text { management of all types of } \\
\text { data; } \\
\text { 5odel as a single source of } \\
\text { information for all } \\
\text { stakeholders; } \\
\text { 6. Search and elimination of } \\
\text { collisions; } \\
\text { 7. Controlling the level of detail } \\
\text { of the model; } \\
\text { 8. Visualization; } \\
\text { 9. Access for all participants. }\end{array}$ & $\begin{array}{c}\text { Revit, } \\
\text { Archicad, } \\
\text { Civil 3D, } \\
\text { Navisworks, } \\
\text { Infrawork, } \\
\text { IndorCAD, } \\
\text { IndorPavement }\end{array}$ & 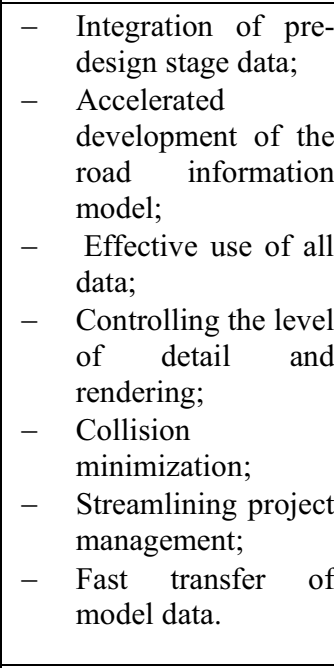 \\
\hline Building & $\begin{array}{l}\text { 1. Fast adjustment of the model } \\
\text { and updating; } \\
\text { 2. Using the information model } \\
\text { as a single source of } \\
\text { information for all interested } \\
\text { parties; } \\
\text { 3. Correction of integrated GIS } \\
\text { data; } \\
\text { 4. Monitoring compliance with } \\
\text { deadlines; } \\
\text { 5. Comparative analysis of the } \\
\text { model; } \\
\text { 6. Ubiquitous access to project } \\
\text { data; } \\
\text { 7. Construction control and } \\
\text { technical supervision based on } \\
\text { digital data. }\end{array}$ & $\begin{array}{l}\text { Navisworks, } \\
\text { BIM360 }\end{array}$ & 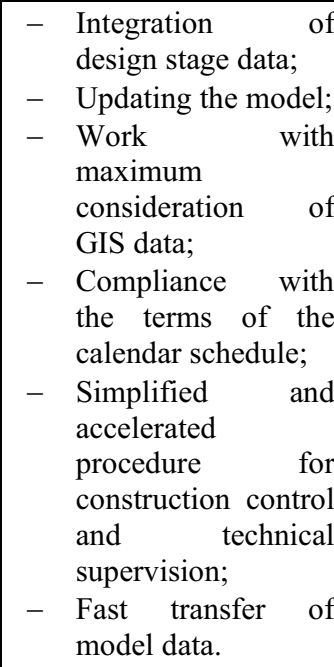 \\
\hline
\end{tabular}




\begin{tabular}{|c|c|c|c|}
\hline Exploitation & $\begin{array}{l}\text { 1. Using the information model } \\
\text { as a single source of } \\
\text { information for all interested } \\
\text { parties; } \\
\text { 2. Monitoring of technical } \\
\text { condition; } \\
\text { 3. Fast access to data; } \\
\text { 4. Simultaneous consistent } \\
\text { management of all types of } \\
\text { data. }\end{array}$ & $\begin{array}{l}\text { Navisworks, } \\
\text { BIM360, } \\
\text { IndorRoad }\end{array}$ & $\begin{array}{l}\text { - Integration of data } \\
\text { from all stages of } \\
\text { the life cycle; } \\
\text { - } \text { Automated } \\
\text { monitoring; } \\
\text { - Fast transfer of } \\
\text { model data. }\end{array}$ \\
\hline Demolition & $\begin{array}{l}\text { 1. Using the information model } \\
\text { as a single source of } \\
\text { information for all interested } \\
\text { parties; } \\
\text { 2. Development of the project; } \\
\text { 3. Correction of integrated GIS } \\
\text { data; } \\
\text { 4. 4. Monitoring compliance } \\
\text { with deadlines; } \\
\text { 5. Monitoring compliance with } \\
\text { deadlines. }\end{array}$ & $\begin{array}{l}\text { Navisworks } \\
\text { Revit, } \\
\text { Archicad, } \\
\text { BIM360 }\end{array}$ & $\begin{array}{l}\text { - Integration of data } \\
\text { from all stages of } \\
\text { the life cycle; } \\
\text { - Compliance with } \\
\text { the terms of the } \\
\text { calendar schedule; } \\
\text { - Simplified and } \\
\text { accelerated control } \\
\text { procedure; } \\
\text { - } 4 \mathrm{D} \text { design. }\end{array}$ \\
\hline
\end{tabular}

For various transport objects, the tasks and effect of BIM tools will vary depending on the source data of the object. However, as a result, the implementation of information modeling technologies for transport infrastructure objects at all stages of the life cycle will be based on the rational use of data in BIM tools. When analyzing the life cycle without using information modeling technologies (Fig. 2, a) and using (Fig. 2, b), one can see significant differences in the transfer and accumulation of data about the construction object.

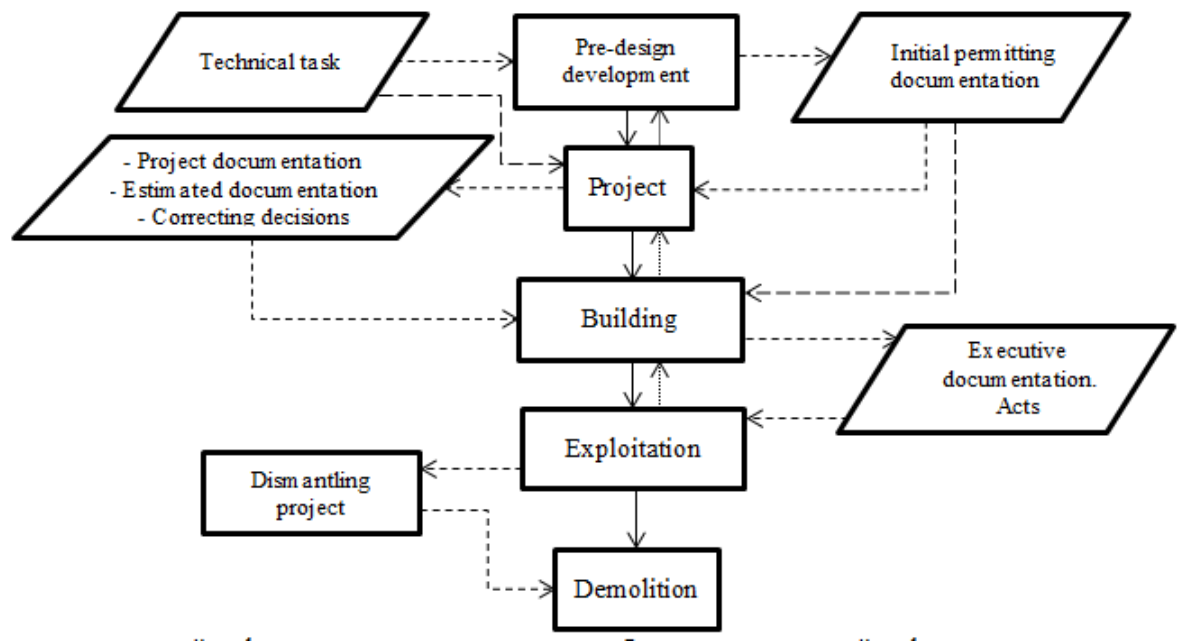

Fig. 2a. Life cycle without the use of information modeling technologies 


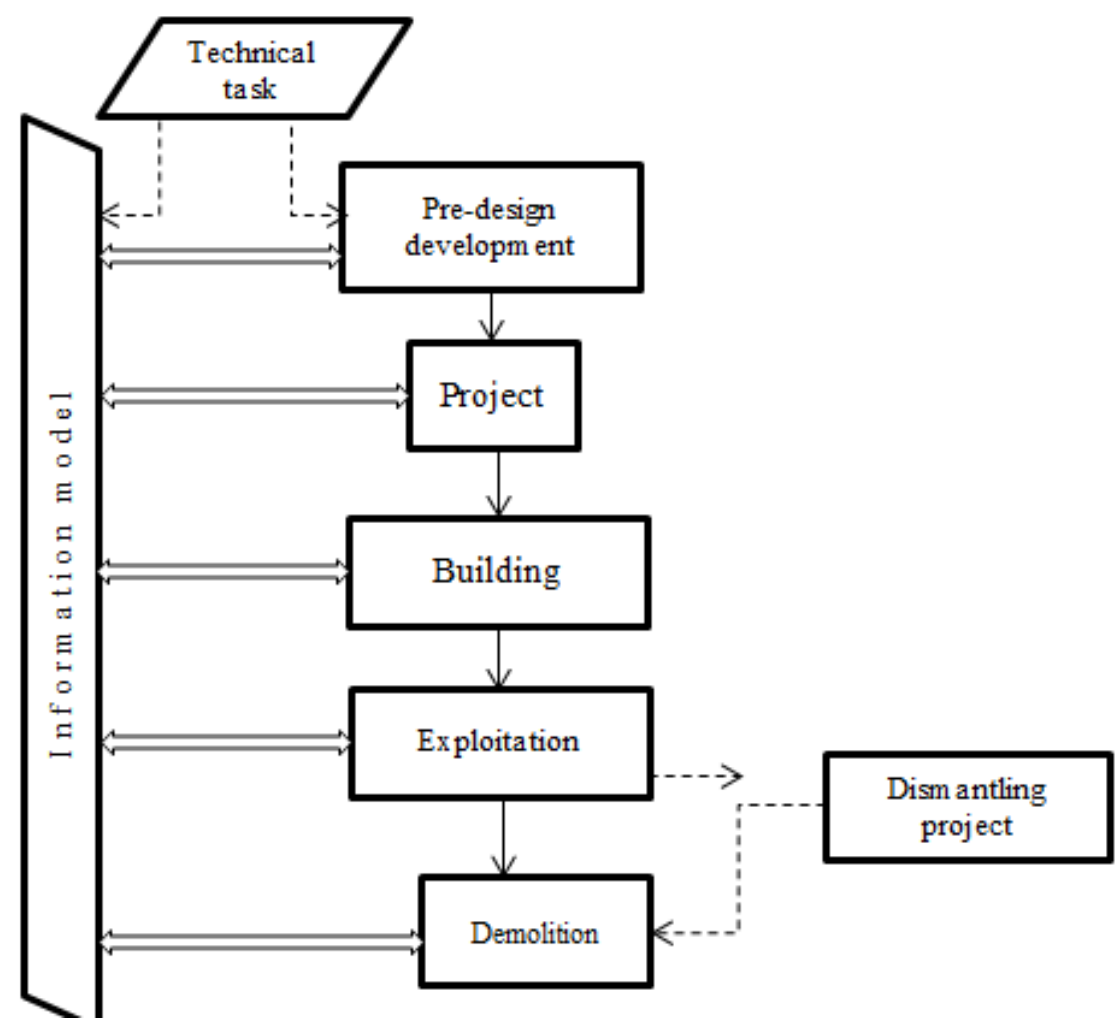

Fig. 2b. Life Cycle Using Information Modeling Technologies

The life cycle with the use of information technology simplifies the transfer of data, which ultimately not only speeds up interaction, but also minimizes the loss of information, its duplication, repeated manipulations and the cost of developing project documentation.

Therefore, it is most expedient to use information modeling technologies at the stage of pre-design development. The formation of the model at the earliest stages of work will be the basis for further updating the model and increasing its detailing during the transition to the next stage of the life cycle of a transport infrastructure object.

\section{Discussion and Conclusions}

Thus, information modeling technologies for transport infrastructure facilities are a modern innovative approach for the design and construction of new transport facilities, which is based on the total capabilities of the latest achievements in the field of digitalization. Already today, specialists in the field of construction of transport facilities have the opportunity to significantly save time and material resources at every stage of the life cycle.

However, to maximize the positive effect, it is also necessary to have technical capacities, methods and algorithms of work, a regulatory framework, the continuous development of new implementation tools, as well as the formation of requirements for the levels of model detailing, design standards and updating. A promising direction in the field of information modeling technologies for transport infrastructure objects is the maximum implementation of coherent information into the model. The leading position among potential data today is occupied by GIS data, which is of great importance precisely in 
transport construction. The use of a digital terrain model at the initial stages of the life cycle provides an informational foundation for further development.

The reported study was funded by RFBR, Sirius University of Science and Technology, JSC Russian Railways and Educational Fund "Talent and success", project number 20-38-51013

\section{References}

1. Rybakova A and Kagan P 2019 E3S Web of Conferences 9701008

2. Zheleznov M and Rybakova A 2021 IOP Conference Series: Materials Science and Engineering 1083012047

3. Kaewunruen S, Sresakoolchai J and Zhou Z 2020 Sustainability 12(6) 2436

4. Moselhi O, Bardareh H and Zhu Z 2020 Applied Sciences 10(8) 2846

5. Ginzburg A 2017 Bulletin of construction technique 12 (1000) 33-35

6. Lua Y, Wub Z, Changa R and Lib Y 2017 Automation in Construction 83 134-148

7. Makisha E 2019 Scientific journal «Modeling, Optimization and Information Technology» 7(2) 339-350

8. Ilhan B and Yaman H 2016 Automation in Construction 70 26-37

9. Mohamed M, Ahmed O 2020 Sustainable Cities and Society 57102120

10. Serene H, Abbas R 2016 Land Use Policy 57 1-10

11. Garyaev N and Rybakova A 2018 MATEC Web of Conferences 1701076

12. Ryzhkova A and Ginzburg A 2020 IOP Conference Series: Materials Science and Engineering $\mathbf{7 5 3} 042067$

13. Ginzburg A, Shilov L and Shilova L 2020 IOP Conference Series: Journal of Physics 1425012156

14. Mironov A, Gershman I, Gershman E and Zheleznov M 2017 Journal of Friction and Wear 38(2) 87-91

15. Kuzina O 2020 IOP Conference Series: Materials Science and Engineering 869062044

16. Tang F, Ma T, Zhang J, Guan Y anf Chen L 2020 Automation in Construction 113 103152

17. Fabozzi S, Salvatore Biancardo S A, R and Bilotta E 2021 Tunnelling and Underground Space Technology 108103723

18. Atazadeh B, Olfat H, Rajabifard A, Kalantari M, Shojaei D and Marjani A M 2021 Land Use Policy 104105367

19. Chapman D, Providakis S and Rogers C 2020 Underground Space 5(4) 354-361

20. Costin A, Adibfar A, Hu H and Chen S S 2018 Automation in Construction 94 257-281 